ISSN 1518-3483

Licenciado sob uma Licença Creative Commons

\title{
Contribuições da teoria da complexidade para a inovação no planejamento pedagógico do ensino superior
}

Contributions of the complexity theory to pedagogical

planning innovation in the higher education

Contribuciones de la teoría de la complejidad para la innovación en la planificación pedagógica de la enseñanza superior

\section{Rosane de Mello Santo Nicola, Marilda Aparecida Behrens*}

\section{Resumo}

Este artigo visa a identificar elementos que apontam para uma postura interdisciplinar de 18 docentes de uma instituição privada de ensino superior, expressos nos programas de disciplina produzidos durante oficinas de formação continuada institucional, com apoio da Finep - Inovação e Pesquisa, em 2016. Nesse contexto, os docentes são desafiados a superar a visão tradicional de ensino e buscar metodologias de aprendizagem ativa para inovar 
sua prática pedagógica. Trata-se de uma pesquisa qualitativa do tipo estudo exploratório que, com base na teoria da complexidade (MORIN, 2000), realiza uma análise documental dos programas, considerando os itens que compõem o documento, por meio de categorias de análise, como integração e inter-relação entre as partes. A análise aponta para ementas integradoras de temas de estudo; uso expressivo de aprendizagem por pares, aprendizagem baseada em problemas e sala de aula invertida; 15 programas com resultados de aprendizagem que preveem aspectos interdisciplinares orientados para a lógica procedimental, na busca da funcionalidade social (profissionalizante); e três programas com resultados de aprendizagem que propõem aspectos interdisciplinares voltados para a lógica subjetiva, dirigida para as dimensões humanas e afetivas. Os resultados revelam avanços de postura interdisciplinar do professor no modelo de programa de disciplina proposto. Essa visão integradora do planejamento prepara o docente para uma abordagem interdisciplinar e representa um exercício relevante de compreensão da unicidade e complexidade do fato educativo.

Palavras-chave: Complexidade. Docência universitária. Interdisciplinaridade. Planejamento pedagógico.

\begin{abstract}
The purpose of this article is to identify elements indicating an interdisciplinary stance expressed in the course syllabi produced by 18 members of a private university teaching staff during institutional continuing education workshops supported by FINEP in 2016. In such context, the professors were challenged to overcome the traditional teaching view and seek active learning methodologies to innovate their teaching practices. It is a qualitative exploratory study research that carries out a document analysis of the syllabi, based on the complexity theory (MORIN, 2000), and considers the items that form the document through analysis categories such as integration and interrelation between the parties. The analysis indicates syllabi that integrate study topics; expressive use of peer learning, problem based learning and flipped classroom; 15 syllabi with learning results that foresee interdisciplinary aspects oriented toward procedural logic in search of social functionality (vocational); 3 syllabi with learning results that propose interdisciplinary aspects oriented
\end{abstract}


toward subjective logic, addressing affective and humane dimensions. The results reveal advances in the professors' interdisciplinary stance with the proposed syllabus model. This integrating view of planning prepares the professor for an interdisciplinary approach and represents a relevant exercise of understanding the unicity and complexity of the educational project.

Keywords: Complexity. University teaching. Interdisciplinarity. Pedagogical planning.

\section{Resumen}

Este artículo tiene por objeto identificar elementos que apuntan a una postura interdisciplinaria de 18 docentes de una institución privada de enseñanza superior, expresados en los Programas de Disciplina producidos durante talleres de formación continuada institucional, con apoyo del FINEP, en 2016. En este contexto, los docentes son desafiados a superar la visión tradicional de enseñanza y buscar metodologías de aprendizaje activo para innovar su práctica pedagógica. Se trata de una investigación cualitativa del tipo estudio exploratorio que, con base en la teoría de la complejidad (MORIN, 2000), realiza un análisis documental de los programas, considerando los ítems que componen el documento por medio de categorías de análisis como integración e interrelación entre las partes. El análisis apunta a la integración de temas de estudio; el uso expresivo de aprendizaje por pares, el aprendizaje basado en problemas y el aula invertida; 15 programas con resultados de aprendizaje que suponen aspectos interdisciplinarios orientados a la lógica procedimental en la búsqueda de la funcionalidad social (profesional); 3 programas con resultados de aprendizaje que se proponen interdisciplinarios, volcados hacia la lógica subjetiva, dirigida a las dimensiones humanas y afectivas. Los resultados revelan progresos en cuanto a la postura interdisciplinaria del profesor en el modelo de Programa de Disciplina propuesto. Esta visión integradora de la planificación prepara al docente para un enfoque interdisciplinario y representa un ejercicio relevante de comprensión de la unicidad y complejidad del hecho educativo.

Palabras clave: Complejidad. Docencia universitaria. Interdisciplinariedad. Planificación pedagógica. 


\section{Introdução}

$\mathrm{Na}$ educação superior, o ensino tem assumido uma concepção conservadora e tradicional que privilegia disciplinas conteudistas, com foco na técnica pela técnica, divididas em tópicos estanques, voltadas à transmissão de conhecimentos específicos de uma dada área de formação e que nem sempre correspondem às necessidades do profissional que se pretende formar. Nessa perspectiva, o corpo docente tem qualificação/ especialização elevada para atuar na área específica, mas, em geral, encontra-se em descompasso e, muitas vezes, apresenta desconhecimento da área pedagógica (PIMENTA; ANASTASIOU, 2002).

A atuação do docente universitário, normalmente, baseia-se na imitação de seus antigos professores. Assim, na sala de aula, predomina a pedagogia da transmissão, por meio de aulas expositivas, com foco na reprodução do conhecimento, em que o estudante assume um papel de ouvinte passivo e o ensino está centrado no professor como emissor de conteúdos. Com essa postura conservadora e reducionista, o aluno recebe a mensagem do professor conforme sua concepção epistemológica (SANTOS; SILVA, 2014).

$\mathrm{Na}$ realidade, a educação superior tende a atender ao paradigma conservador, proposto no século XVII, que dá destaque à razão e à fragmentação do conhecimento, da qual se originou uma visão linear, sectária e mecânica dos fenômenos no mundo. Segundo Nicolescu (1999, p. 14),

a ciência moderna nasceu de uma ruptura brutal em relação à antiga visão de mundo. Ela está fundamentada numa ideia, surpreendente e revolucionária para a época, de uma separação total entre individuo conhecedor e a Realidade, tida como completamente independente do indivíduo que a observa. Mas, ao mesmo tempo, a ciência moderna estabelecia três postulados fundamentais, que prolongavam, a um grau supremo, no plano da razão, a busca de leis e da ordem.1) A existência de leis universais, de caráter matemático; 2) A descoberta destas leis pelas experiências científicas; 3 ) A reprodutividade perfeita dos dados experimentais. 
Esses construtos foram instaurados pelo paradigma da simplicidade, também denominado newtoniano-cartesiano, baseado na razão e na fragmentação, que surgiu no século XVII, estendendo-se pelo século XX e adentrando o século XXI (MORIN, 2000). Nesse sentido, a ciência dessacraliza o universo da visão dogmática e passa a tratá-lo como uma máquina, pois o conhecimento dominante e pertinente advém de leis objetivas e deterministas. Segundo Behrens (2015), esse pensamento gera uma visão compartimentada, mecânica, disjuntiva e reducionista, pois separa o todo, que é complexo no mundo, divide o que é naturalmente ligado, baseia os ensinamentos em conteúdos fragmentados, reduz os problemas e produz uma visão positivista e artificializada dos fenômenos, causando uma aprendizagem sem significado, por isso esquecida com facilidade pelos alunos.

Entretanto, no século XXI, com as mudanças sociais e a evolução da revolução informacional, fruto do desenvolvimento científico e tecnológico, exige-se um rompimento com o paradigma simplificador vigente, requerendo da humanidade outras visões, dimensões, princípios e saberes que sustentem um preparo mais amplo e relevante para o ensino em geral, mas, em especial, para o egresso da educação superior. Serra e Becker (2011) relatam que, nos anos 1990, a intensificação de mudanças na dinâmica do capitalismo internacional configurou a globalização, provocando a mundialização dos mercados e, em consequência, novas formas de gestão do trabalho. De modo complementar, Deluiz (1996) explica que o perfil do trabalhador mudou, sendo requeridas dele capacidades de trabalhar em equipe, fazer diagnósticos, resolver problemas, tomar decisões, intervir no processo de trabalho, auto-organizar-se e enfrentar situações de constantes mudanças.

Essa contradição entre a formação universitária e as demandas do mundo do trabalho extrapola a simples formação profissional, com vistas a atender ao mercado, pois se faz necessário formar um indivíduo preparado para ser agente de transformação social, com visão abrangente e sistêmica, além de ter autonomia intelectual e profissional. 
Com essa problemática exposta, busca-se investigar a seguinte questão: os planos de ensino elaborados por professores universitários que frequentam oficinas sobre inovação metodológica da prática pedagógica durante processos de formação continuada voltados à superação do paradigma tradicional na docência já apresentam construtos que avançam para a visão de interdisciplinaridade? Propõe-se, então, o seguinte objetivo: analisar a presença de construtos que apontam para uma postura interdisciplinar nos planos de ensino de docentes universitários de uma instituição privada de ensino superior, envolvidos em processo de formação continuada, composto por oficinas sobre inovação metodológica da prática pedagógica.

Este artigo pretende ajudar a refletir sobre a necessidade de se romper com a atual organização curricular no ensino superior, sedimentada em uma lógica secular de fragmentação e centrada em conteúdos específicos e cumulativos, desarticulados, organizados por meio de tópicos estanques e que seguem uma visão linear, do mais simples para o mais complexo.

Para tanto, investigam-se os pressupostos epistemológicos que caracterizam uma visão inovadora na educação superior, que, neste momento, aponta para a teoria da complexidade, proposta por Morin (2000) e cujo ponto central é provocar a mudança paradigmática ou a reforma do pensamento na ciência e na educação. Assim, optou-se por investigar os construtos necessários para atender ao desafio proposto pela urgência de buscar uma visão da totalidade, global, complexa, que propõe a religação dos saberes (MORIN, 2000), acolhe o indivíduo em suas múltiplas dimensões e considera a ecologia global. Neste século XXI, impõe-se fortemente a superação dos princípios cartesianos e simplistas, baseados na razão e exilados da emoção, que geraram a fragmentação do conhecimento. Nesse movimento de mudança paradigmática, a proposição de transpor a visão disciplinar apresenta-se na proposta da interdisciplinaridade, que advém de um movimento iniciado no século $\mathrm{XX}$, quando passou a ser requerida a religação dos saberes. A interdisciplinaridade pode ser considerada, portanto, o primeiro passo em direção àquela mudança epistemológica exigida pela ciência e pela sociedade contemporânea. 


\section{Teoria da complexidade e planejamento do trabalho pedagógico: relações nem sempre perceptíveis}

O novo paradigma da complexidade, conforme Morin (2000), concebe a articulação e reunificação das partes, reagrupando os saberes e buscando a unidade na diversidade, numa perspectiva integradora e complexa, pois, por meio dessa organização do todo, configura-se a interconexão de conhecimentos que permite considerar a visão de contexto. Nesse sentido, o pensamento complexo significa a cooperação, que valoriza e restabelece as relações e as atitudes significativas, aproximando a emoção e a intuição da razão. Não se trata de retomar a pretensão do pensamento simplificador, de controlar e dominar o real, mas de exercer um pensamento capaz de lidar com o real, dialogando e negociando com ele. A esse respeito, cabe a contribuição de Oliveira (2003, p. 59), quando esclarece que essa é uma

relação que amplia a consciência de mundo do indivíduo e a reelaboração do pensamento, em que o ser humano enquanto homus complexus se reconhece como responsável pela própria auto-organização, pelo estabelecimento das relações com o outro (alteridade) e pela auto-eco-organização.

Para Torres e Behrens (2014, p. 17), “a visão complexa, holística e ecológica abriga a subjetividade, a intuição e a emoção" e, especialmente, "a busca de uma vida melhor e mais qualificada dos homens e mulheres e do próprio planeta". As autoras explicam que esse novo paradigma da ciência desafia todas as organizações, mas, particularmente, as instituições de ensino, pois elas requerem a mudança urgente na prática pedagógica dos professores. Faz-se necessário "desenvolver uma abordagem pedagógica que gere um ensino inovador, alternativo, midiatizado, flexível, individualizado e/ou colaborativo" (TORRES; BEHRENS, 2014, p. 18).

Nesse movimento de mudança paradigmática, a prática docente ainda tem se apresentado pelo "pensamento linear e reducionista" (MORIN, 2000, p. 35), pois a própria composição das universidades atende à divisão "do conhecimento em áreas, as áreas em cursos, os cursos em semestres, os semestres em disciplinas, as disciplinas em unidades" (TORRES; BEHRENS, 2014, 
p. 16). Nesse sentido, há urgente necessidade de superação desse modelo de universidade assentado na fragmentação do conhecimento, atrelada à visão positivista do universo, com currículos lineares e disciplinares, que obedece à lógica do paradigma dominante e conservador e, nessa mesma direção, reduz a docência a aulas expositivas que levam à reprodução do conhecimento.

Esse panorama é reforçado por uma lógica operacional nas instituições públicas e privadas brasileiras, originada pela ausência de uma política de governo que requer das universidades a formação pedagógica continuada dos docentes universitários. Sem exigência de conhecimentos de base para o magistério superior, essa lógica ainda representa espaço de "atividade assistemática, com escasso rigor e pouca investigação” (MARCELO GARCÍA, 1999, p. 248).

Somente na última década, houve maior preocupação com a formação do professor universitário no Brasil, porém, muitas vezes, reforçando uma perspectiva instrumental de treinamento ou aperfeiçoamento para solução de situações imediatas. Tais iniciativas podem contribuir para a continuidade da fragmentação identitária dos docentes ou mesmo para a lógica reprodutiva do paradigma conservador.

Decorrente dessa dinâmica, o planejamento do trabalho docente ainda se efetiva por meio de um exercício isolado, fruto de uma conjuntura estrutural caracterizada, principalmente, pela intensificação das atividades docentes no ensino superior e pela ausência de uma política curricular integrada e construída coletivamente (OLIVEIRA, 2003). É evidente que a forma como o professor concebe a educação, o ensino, a aprendizagem e o sujeito aprendiz reflete na sua atuação docente, a qual está pautada em saberes que se constroem na formação profissional, na prática pedagógica e nas relações estabelecidas no cotidiano do espaço de trabalho (TARDIF, 2002).

Assim, a atual organização do trabalho pedagógico não favorece a discussão coletiva e a parceria, ocorrendo a desarticulação entre os docentes que trabalham no mesmo período, com a mesma turma de um curso de graduação. Faltam condições de trabalho que propiciem o surgimento de ações educativas que, integradas, possibilitem significado para a docência 
universitária a partir dos relacionamentos construídos pela convivência entre os professores e seus pares e entre eles e os estudantes.

Por outro lado, o trabalho em conjunto representa apenas o ponto de partida da construção do trabalho coletivo, sendo necessário que os docentes compartilhem os avanços da ciência, os paradigmas inovadores, as várias visões, contradições e conflitos, para construir algo novo, que, embora possa não ser ideal, representa o possível naquele momento e atende aos anseios e às expectativas de mudança do grupo. Os professores aprendem uns com os outros, considerando que o grupo social é o espaço privilegiado de aprendizagens significativas dos sujeitos, preferencialmente no locus da universidade.

Nessa perspectiva, cabe lembrar também que a necessidade do trabalho em conjunto diz respeito à autonomia relativa do trabalho docente, uma vez que está sempre vinculado a um plano alheio pertencente à proposta da instituição de ensino superior. A autonomia docente, muito discutida pelos teóricos da educação na literatura, como Adorno (1995) e Contreras (2002), e em eventos acadêmicos, é compreendida aqui como uma autonomia relativa, pois, em geral, os profissionais atendem aos parâmetros propostos pela instituição de ensino. Essa relativa sujeição docente merece uma ação reflexiva durante a formação continuada, a fim de que o profissional perceba a necessidade de se integrar a um projeto coerente de formação inicial, representado pelo curso de graduação no qual está inserido.

\section{A interdisciplinaridade: desafios da lógica acadêmica atual}

Apesar de estar presente nos documentos oficiais e nos textos dos projetos pedagógicos, a interdisciplinaridade continua, por inúmeras razões, como meta ainda distante de ser alcançada, um fazer que se almeja, mas que ainda carece de encontrar efetiva implementação.

Nesse sentido, cabe lembrar a explicação da Coordenação de Aperfeiçoamento de Pessoal de Nível Superior (CAPES, 2013, p. 1) quando da criação da área de avaliação "interdisciplinar", como sendo resultante "da 
necessidade de se dar conta de novos problemas que emergem no mundo contemporâneo, de diferentes naturezas e com variados níveis de complexidade, muitas vezes decorrentes do próprio avanço dos conhecimentos científicos e tecnológicos". Essa iniciativa influenciou a criação de cursos inovadores e interdisciplinares na pós-graduação brasileira, "tendência mundial de aumento de grupos de pesquisa e programas acadêmicos com foco em questões complexas" (CAPES, 2013, p. 11).

Embora a interdisciplinaridade seja compreendida como condição sine qua non para o ensino e a pesquisa na sociedade contemporânea, o uso excessivo do termo aproxima-se da banalização, podendo desvirtuar o conceito para uma aparente facilidade e estabilidade que estão longe de se alcançar, principalmente, na educação superior.

Carvalho (2004) destaca a impossibilidade de a prática interdisciplinar efetivar-se de modo cômodo ou estável, pois requer uma nova forma de conceber o campo da produção de conhecimento que supere uma concepção disciplinar. Um dos resultados dessa situação é a superposição de conteúdos, caracterizando o processo como multi ou pluridisciplinar, mas que ainda não atinge propostas interdisciplinares (SANTOS, 2006).

Tanto a pluri quanto a multidisciplinaridade podem ser designadas como justaposição de conteúdos de disciplinas heterogêneas ou, ainda, integração de conteúdos numa mesma disciplina (FAZENDA, 1979). Em ambas, recorre-se a informações de várias disciplinas para estudar um determinado fenômeno, sem interligá-las. Assim, analisando, por exemplo, um romance, tarefa da literatura, pode-se recorrer à linguística, à história, à filosofia ou à política, cada qual com sua contribuição específica, mas sem integração efetiva entre elas. Esse modo de relacionar disciplinas é considerado ainda incipiente, porque dificilmente ocorre uma articulação que ultrapasse a tão criticada fragmentação dos conhecimentos (SANTOS, 2006). Conforme Nicolescu (1999, p. 45-46), a pluridisciplinaridade "diz respeito ao estudo de um objeto de uma mesma e única disciplina por várias disciplinas ao mesmo tempo".

Faz-se necessária uma organização curricular no ensino superior que favoreça a interdisciplinaridade, visto que os saberes requeridos pelo mundo do trabalho não coadunam com a fragmentação do conhecimento 
representada pela organização estanque de disciplinas que não dialogam entre si. Essa interdisciplinaridade requer uma nova forma de concepção do campo de conhecimento que suplante o contexto da lógica acadêmica disciplinar atual. Como tal, pode ser definida como um ponto de cruzamento entre atividades - disciplinares e interdisciplinares —, cujas lógicas distintas buscam equilíbrio. Uma é racional e, portanto, voltada à análise fragmentada, enquanto a outra é subjetiva, orientada à síntese simplificadora (LEIS, 2005).

A prática interdisciplinar autêntica constrói-se com uma nova atitude frente ao conhecimento por parte dos docentes, os quais necessitam romper com os limites disciplinares. Para tanto, precisam deixar de defender o conteúdo da sua disciplina como o mais importante para o aprendizado do estudante, entendendo-o como parte integrante e integradora da construção do conhecimento discente. Carvalho (2004, p. 120) esclarece que essa prática visa à

abertura de um espaço de mediação entre conhecimentos e articulação de saberes, no qual as disciplinas estejam em situação de mútua coordenação e cooperação, construindo um marco conceitual e metodológico comum para a compreensão de realidades complexas. A meta não é unificar as disciplinas, mas estabelecer conexões entre elas, na construção de novos referenciais conceituais e metodológicos consensuais, promovendo a troca entre os conhecimentos disciplinares e o a diálogo dos saberes especializados com os saberes não científicos.

Assim, a interdisciplinaridade aproxima-se da noção de conhecimento complexo, entendido como um conhecimento pleno em sua provisoriedade e que requer, segundo Morin (2000), o diálogo entre as partes e o todo, e vice-versa. Se complexo, etimologicamente, é o que se tece junto, conforme esse intelectual, a abordagem de ensino abrange os processos de análise e síntese, uma vez que só se pode conhecer quando se fragmenta o real, isolando um objeto do todo do qual faz parte; entretanto, é possível articular os saberes resultantes dessa fragmentação, reconhecendo as relações entre o todo e as partes, projetando-se uma visão mais ampla e complexa do conhecimento, e, embora não se restitua a totalidade, pode-se entender e combater a desagregação. 
Por outro lado, sem pretender explorar o embate teórico, epistemológico e metodológico, busca-se destacar a prática interdisciplinar, com vistas a entender e valorizar o aspecto experimental e inovador da práxis proposta nesta pesquisa.

Exatamente para entender as diferentes concepções que fundamentam essa prática, vale citar Lenoir e Hasni (2004), que definem três conceitos de interdisciplinaridade, com propósitos e dimensões distintas (Quadro 1).

Quadro 1-Conceitos de interdisciplinaridade para uso em contextos formadores.

\begin{tabular}{l|l|l}
\hline Origem & Propósito & Características \\
\hline $\begin{array}{l}\text { Cultura científica } \\
\text { francesa }\end{array}$ & $\begin{array}{l}\text { Construir explicação de } \\
\text { racionalidade científica para a } \\
\text { questão da interdisciplinaridade. }\end{array}$ & $\begin{array}{l}\text { Dimensão epistemológica. Centrada } \\
\text { na busca de significado (abstrato). }\end{array}$ \\
\hline $\begin{array}{l}\text { Cultura científica } \\
\text { norte-americana }\end{array}$ & $\begin{array}{l}\text { Construir explicação marcada pela } \\
\text { lógica instrumental. }\end{array}$ & $\begin{array}{l}\text { Dimensão metodológica. Orientada } \\
\text { para a busca da funcionalidade social } \\
\text { (profissionalizante). }\end{array}$ \\
\hline $\begin{array}{l}\text { Cultura científica } \\
\text { brasileira } \\
\text { emergente }\end{array}$ & $\begin{array}{l}\text { Promover condições para a } \\
\text { autorrealização humana numa } \\
\text { lógica subjetiva. }\end{array}$ & $\begin{array}{l}\text { Dimensões humanas e afetivas. } \\
\text { Dirigida à procura do próprio ser. } \\
\text { Propõe atividade interdisciplinar } \\
\text { destinada à busca de respostas para } \\
\text { perguntas pessoais e à realização } \\
\text { de um trabalho cooperativo entre } \\
\text { os sujeitos do processo educativo. } \\
\text { Perspectiva fenomenológica e de } \\
\text { interação simbólica. }\end{array}$ \\
\hline
\end{tabular}

Fonte: Adaptado de Lenoir e Hasni (2004).

Com base nessas três representações de interdisciplinaridade, procurou-se identificar elementos que apontem para uma postura interdisciplinar de 18 docentes de uma instituição privada de ensino superior, expressa nos programas de disciplina produzidos durante oficinas de formação continuada institucional. A escolha dos programas de disciplina como objeto de análise documental desta pesquisa deve-se ao fato de representarem o documento que converge para o cotidiano do ensino, constituindo, por excelência, o espaço de confluência entre conhecimento e 
ensino. Sua análise pode contribuir para desvendar as práticas cotidianas do mundo acadêmico. Não são, portanto, produções isentas, ingênuas, pois traduzem leituras e modos de interpretação do vivido por um determinado grupo de pessoas, em um dado tempo e espaço.

\section{Procedimentos metodológicos}

As contribuições aqui apresentadas advêm de uma pesquisa qualitativa, do tipo estudo exploratório, que, conforme Creswell (2007), designa estudos cuja temática ou população ainda foi pouco pesquisada e em que o pesquisador tenta construir um entendimento sobre ela. Com essa opção metodológica, foi possível incluir uma análise documental de programas de disciplina dos docentes universitários participantes; alguns professores, oriundos de diferentes áreas do conhecimento, estavam envolvidos em processo de formação continuada e foram desafiados a superar a visão tradicional de ensino e buscar elementos/construtos interdisciplinares para inovar sua prática pedagógica.

Com esse propósito, foram definidas as seguintes unidades de análise: integração de conteúdos relacionando as partes ao todo; inter-relação de processos e disciplinas do curso; relação entre teoria e prática; e promoção do trabalho cooperativo. Para contribuir com o estudo, foram criadas categorias, para selecionar informações nos planejamentos das disciplinas investigados, ou seja: o completo preenchimento dos itens que compõem o documento Plano de Ensino da disciplina; a atualização das referências; a ementa da disciplina; a relação estabelecida com disciplinas precedentes e posteriores; os resultados de aprendizagem; o mapa mental que articula os conceitos-chave da disciplina; a metodologia e a avaliação da aprendizagem.

Os programas desta análise foram produzidos por professores que participam de projetos-piloto de inovação no ensino de graduação, vinculados ao financiamento da Finep - Inovação e Pesquisa e ao Programa de Inovação na Graduação da Instituição de Ensino Superior. 
No primeiro semestre de 2016, esses professores atenderam a um edital interno da universidade para docentes que desejavam desenvolver um piloto de inovação metodológica de sua prática pedagógica, em uma disciplina de graduação, a ser ministrada no primeiro semestre de 2017, além da redação de um artigo científico com o relato dessa vivência. Cabe destacar que os docentes que se propuseram a participar do Programa de Inovação na Graduação foram remunerados, sendo requerido que participassem de todas as oficinas de formação continuada, bem como da produção científica sobre sua própria prática.

Esse programa envolveu temas que subsidiassem o uso de metodologias de aprendizagem ativa, acolhendo a visão interdisciplinar. O plano-piloto da pesquisa aconteceu em três fases, cada qual com duração estimada de 30 horas de atividades, sem contar as horas letivas.

As três fases da pesquisa foram assim desenvolvidas: (i) a primeira, realizada no segundo semestre de 2016, foi composta por oficinas de formação continuada, planejamento da disciplina e organização de um Plano de Ensino para a implementação de uma proposta de aprendizagem ativa no primeiro semestre de 2017; (ii) a segunda foi dedicada à aplicação do Plano de Ensino desenvolvido na disciplina planejada, bem como à apresentação de relatórios ao setor responsável sobre o andamento e os resultados da proposta implementada; (iii) a terceira, a ser realizada no segundo semestre de 2017, será constituída pela avaliação dos resultados e redação de um artigo científico.

$\mathrm{Na}$ primeira fase do projeto, foi desenvolvido o planejamento da disciplina, na forma de programa de disciplina, no qual foi requisitado que estivessem descritas as ações inovadoras e a proposta de avaliação da aprendizagem a ser implementada. Cabe destacar que o modelo do programa de disciplina foi determinado pela equipe responsável pela formação dos docentes, sendo novo para todos da instituição. Portanto, a elaboração dos programas pelos professores foi realizada durante a formação continuada, por meio de metodologias de aprendizagem ativa aplicadas nas oficinas pelas formadoras. Tal programa apresenta a estrutura descrita no Quadro 2. 
Quadro 2 - Quadro-síntese da estrutura do programa de disciplina.

\begin{tabular}{|c|c|}
\hline Componente & Descrição/orientação dos itens de cada parte \\
\hline $\begin{array}{l}\text { Dados de } \\
\text { identificação }\end{array}$ & $\begin{array}{l}\text { Nome da disciplina, nome do professor, curso e período a que se destina, } \\
\text { carga horária, créditos e turno. }\end{array}$ \\
\hline Ementa & $\begin{array}{l}\text { Texto coeso com } 60 \text { palavras, contendo público-alvo, conteúdo central, } \\
\text { principais temas de estudo e objetivo de aprendizagem esperado no fim } \\
\text { da disciplina. Deve motivar o interesse do estudante pela disciplina e ser } \\
\text { escrito de forma a permitir que se perceba a articulação existente entre os } \\
\text { temas de estudo. }\end{array}$ \\
\hline $\begin{array}{l}\text { Relação } \\
\text { estabelecida com } \\
\text { outras disciplinas } \\
\text { precedentes e } \\
\text { posteriores }\end{array}$ & $\begin{array}{l}\text { Explicar como temas de estudo trabalhados em disciplinas anteriores } \\
\text { contribuem para a aprendizagem da disciplina. Anunciar, também, como e } \\
\text { para quais disciplinas que virão no decorrer do curso os temas de estudo } \\
\text { trabalhados contribuirão. }\end{array}$ \\
\hline Temas de estudo & $\begin{array}{l}\text { Relacionar todos os temas de estudo que se pretende abordar na } \\
\text { disciplina. }\end{array}$ \\
\hline $\begin{array}{l}\text { Resultados de } \\
\text { aprendizagem }\end{array}$ & $\begin{array}{l}\text { Evidências que atestam o que um estudante sabe, compreende e é } \\
\text { capaz de fazer no fim de um processo de aprendizagem. Explicitar o } \\
\text { desempenho esperado, sendo fundamental para o processo de avaliação } \\
\text { da aprendizagem. Apresentar os resultados de aprendizagem da disciplina, } \\
\text { que devem ser escritos a partir do mapa mental e da ementa, com ênfase } \\
\text { naquilo que os estudantes vão aprender. Precisam ser claros e concisos, } \\
\text { potencialmente mensuráveis e observáveis, adequados ao papel da } \\
\text { disciplina no curso. Para cada resultado de aprendizagem, haverá alguns } \\
\text { indicadores de sucesso. Também é importante estimar o tempo (número } \\
\text { de horas) que se pretende dedicar para que o estudante desenvolva cada } \\
\text { um dos resultados de aprendizagem esperados. Essa estimativa auxiliará } \\
\text { a refletir sobre a importância de cada tema de estudo na disciplina e } \\
\text { escolher a estratégia de ensino e aprendizagem mais adequada. }\end{array}$ \\
\hline Mapa mental & $\begin{array}{l}\text { Conceitos-chave da disciplina apresentados em diagrama e de forma } \\
\text { integrada. }\end{array}$ \\
\hline Metodologia & $\begin{array}{l}\text { Metodologias de aprendizagem ativa empregadas para cada resultado } \\
\text { de aprendizagem e dedicação extraclasse do estudante requerida pelas } \\
\text { metodologias. }\end{array}$ \\
\hline Avaliação & $\begin{array}{l}\text { Indicar a forma de avaliação e o indicador de sucesso referentes a } \\
\text { cada resultado de aprendizagem. Os indicadores de sucesso devem ser } \\
\text { observados enquanto o estudante executa ações ou tarefas específicas } \\
\text { (avaliação formativa), como também ser mensurados (avaliação somativa). } \\
\text { Eles devem conter o nível de desempenho desejado, por meio de } \\
\text { qualificadores, e ser formulados completando a frase: "Para verificar que } \\
\text { meu estudante atingiu o resultado de aprendizagem desejado, cumprindo } \\
\text { as etapas de aprendizagem para alcançá-lo, eu preciso me certificar de que } \\
\text { ele...". }\end{array}$ \\
\hline
\end{tabular}

Fonte: As autoras (2017). 
O acesso aos programas de disciplina deve-se ao fato de uma das autoras desta pesquisa atuar no $\mathrm{CrEAre} \mathrm{da} \mathrm{instituição,} \mathrm{sendo} \mathrm{membro}$ responsável pela formação continuada dos professores. Dos 60 planejamentos produzidos e postados no espaço do setor de formação, 18 ficaram sob responsabilidade dessa formadora, correspondendo a $31,6 \%$. O Quadro 3 descreve a diversidade de áreas do conhecimento desse recorte.

Quadro 3 - Descrição dos programas de disciplina analisados.

\begin{tabular}{|c|c|c|c|}
\hline Curso & Disciplina & $\begin{array}{l}\text { Carga } \\
\text { horária }\end{array}$ & Período \\
\hline \multirow{3}{*}{ Direito } & Human Rights* & $40 \mathrm{~h}$ & Diversos \\
\hline & Direito Societário & $80 \mathrm{~h}$ & 50 \\
\hline & $\begin{array}{l}\text { Estágio Supervisionado de Prática Jurídica } \\
\text { Criminal I }\end{array}$ & $80 \mathrm{~h}$ & 70 \\
\hline \multirow{3}{*}{$\begin{array}{l}\text { Licenciatura em } \\
\text { Filosofia }\end{array}$} & Didática & $80 \mathrm{~h}$ & 3은 \\
\hline & $\begin{array}{l}\text { Educação em Direitos Humanos e Meio } \\
\text { Ambiente }\end{array}$ & $80 \mathrm{~h}$ & 3은 \\
\hline & Teoria do Conhecimento & $80 \mathrm{~h}$ & 3은 \\
\hline \multirow{3}{*}{ Engenharias } & Introdução ao Cálculo & $80 \mathrm{~h}$ & 10 \\
\hline & Sistema de Coleta e Tratamento de Esgotos & $120 \mathrm{~h}$ & 70 \\
\hline & Eletricidade Aplicada & $40 \mathrm{~h}$ & 5은 \\
\hline \multirow{2}{*}{ Psicologia } & Ética & $40 \mathrm{~h}$ & 30 \\
\hline & Psicofarmacologia & $40 \mathrm{~h}$ & 3은 \\
\hline Ciências Biológicas & Anatomia Humana & $80 \mathrm{~h}$ & 10 \\
\hline Nutrição & $\begin{array}{l}\text { Terapia Nutricional de Enfermidades do } \\
\text { Adulto e do Idoso I }\end{array}$ & $120 \mathrm{~h}$ & 30 \\
\hline Agronomia & Fitopatologia I & $54 \mathrm{~h}$ & 5은 \\
\hline $\begin{array}{l}\text { Licenciatura em } \\
\text { Química }\end{array}$ & Química Geral e Inorgânica I & $80 \mathrm{~h}$ & 10 \\
\hline $\begin{array}{l}\text { Relações Públicas/ } \\
\text { Publicidade e } \\
\text { Propaganda }\end{array}$ & Teoria da Comunicação & $80 \mathrm{~h}$ & 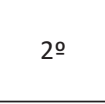 \\
\hline Teatro & História do Teatro Brasileiro I & $40 \mathrm{~h}$ & 30 \\
\hline Pedagogia & Políticas Educacionais e Gestão de Escola & $60 \mathrm{~h}$ & 30 \\
\hline Arquitetura e Design & $\begin{array}{l}\text { Topografia Avançada Aplicada à Arquitetura } \\
\text { e Design }\end{array}$ & $40 \mathrm{~h}$ & 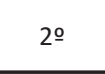 \\
\hline
\end{tabular}

Fonte: As autoras (2017).

Nota: * Disciplina ofertada no English Semester.

Rev. Diálogo Educ., Curitiba, v. 17, n. 52, p. 357-386, abr./jun. 2017 
O universo foi composto por 18 professores universitários, mestres ou doutores, com vínculo empregatício na instituição, que se propuseram a participar desta pesquisa. Conforme o Quadro 3, eles atuam em diversos cursos das áreas de licenciatura e humanidades, politécnica, ciências da vida, arquitetura e design, comunicação e direito.

\section{Principais resultados}

A partir das oficinas, os professores foram orientados a seguir itens específicos para elaborar os programas de disciplina (Quadro 3); desses itens, foram selecionados aqueles considerados essenciais para a análise documental da presença de postura interdisciplinar nesta pesquisa, a saber: (i) a atualização das referências; (ii) a ementa da disciplina; (iii) a relação estabelecida com disciplinas precedentes e posteriores; (iv) os resultados de aprendizagem; (v) o mapa mental articulado dos conceitos-chave da disciplina; (vi) a metodologia e a avaliação da aprendizagem.

Sobre a atualização das referências, todos os Planos de Ensino desta amostra apresentam-nas atualizadas, com indicação de livros adequados aos temas de estudo propostos, bem como artigos científicos de periódicos recentes, ambos datados entre 2000 e 2016, excetuando-se obras clássicas.

Com relação à categoria "ementa da disciplina", os professores foram orientados a escrever um texto coeso, curto e objetivo que permitisse identificar o público-alvo da disciplina e sinalizar o que se esperava dos estudantes no fim dela. Também foram informados de que a intenção da ementa seria motivar o interesse do estudante pela disciplina e de que o texto deveria expressar a articulação existente entre os temas de estudo.

A título de exemplo, apresentam-se duas ementas de disciplina:

[...] os calouros das Engenharias estudam a base da Matemática necessária para assimilar os conceitos do Cálculo Diferencial e Integral. Durante o semestre, o estudante irá realizar operações que envolvam 
as funções algébricas (funções polinomiais e modulares) e transcendentes (exponencial, logarítmicas e trigonométricas). Ao final da disciplina, o estudante é capaz de descrever matematicamente situações-problema de seu cotidiano (Introdução ao Cálculo).

[...] os estudantes de Arquitetura estudam conceitos Topográficos para interpretação, medição e representação do território. Nela, os estudantes realizam levantamentos topográficos, representações tridimensionais, modelagem do terreno, desenhos de plantas, maquetes e mapas. Ao final, o estudante é capaz de produzir e representar soluções adequadas à implantação no terreno para projetos de arquitetura, urbanismo e paisagismo (Topografia Avançada Aplicada à Arquitetura e Design).

Esses exemplos permitem entender a ementa da disciplina não somente como um resumo dos conteúdos que serão trabalhados, mas ficando evidentes três informações essenciais: o conteúdo central (base da matemática necessária para assimilar os conceitos de cálculo diferencial e integral e conceitos topográficos para interpretação, medição e representação do território), os principais temas de estudo (operações de funções algébricas e transcendentes e levantamentos topográficos, representações tridimensionais, modelagem do terreno, desenhos de plantas, maquetes e mapas) e o objetivo de aprendizagem (descrever matematicamente situações-problema do cotidiano e produzir e representar soluções adequadas à implantação no terreno para projetos de arquitetura, urbanismo e paisagismo). Todos os itens estão integrados, compondo um texto coeso.

Nesse aspecto, todos os docentes alcançaram a integração dos elementos que compõem o programa de disciplina, quando, em geral, as ementas são apresentadas em forma de tópicos. Também é possível perceber que os objetivos de aprendizagem propostos na ementa voltam-se, adequadamente, para o estudante, buscando desenvolver processos cognitivos em nível de aplicação (caso de Introdução ao Cálculo) e criação (caso de Topografia), conforme a taxionomia de Andersen (FERRAZ; BELHOT, 2010).

Sobre a categoria "relação da disciplina com outras precedentes e posteriores”, quatro programas, na primeira versão do texto, não a 
atenderam, deixando de situar a disciplina na organização curricular do curso. Em mais três planos, faltavam as disciplinas precedentes e, em outros quatro, as posteriores. Assim, ao todo, havia 11 programas (61\%) sem essa categoria completa. Após orientados e receberem feedback, os docentes reformularam os programas, acrescentando os elementos. Dessa forma, infere-se que se trata de uma prática que evidencia a hierarquia que os conhecimentos guardam entre si na relação de anterioridade e posterioridade, conforme foi explicado aos docentes nas oficinas. As disciplinas precisam ser situadas na organização curricular e o programa de ensino da disciplina é, estrategicamente, o documento ideal para divulgar essa interdependência, tanto para o professor que a ministra quanto para o estudante, que, dessa forma, poderá avaliar suas condições para acompanhá-la. Portanto, isso interfere na inter-relação de processos e disciplinas do curso, pois é sabido que a separação do currículo em disciplinas estanques impede uma verdadeira construção e integração do conhecimento. Por outro lado, se ao menos forem divulgadas as relações entre as experiências anteriores e os novos conteúdos no programa de cada disciplina, haverá mais possibilidade de os docentes planejarem de forma mais coerente e de os alunos obterem melhor aproveitamento.

Quanto aos mapas mentais, dois programas de disciplina, na primeira versão entregue, não apresentaram esse item solicitado; trata-se de um tópico que requer do docente a seleção e integração dos conteúdos centrais da disciplina. Também num mapa mental, a disciplina é representada como uma rede de palavras-chave que devem expressar conceitos essenciais, cuja relevância reside na função da potencialidade formativa e não apenas na importância disciplinar (ZABALA, 1998). Após orientação, completaram os programas, sem dificuldade, tendo em vista que a proposta de produção é bastante livre e flexível para que o docente elabore algo criativo e motivador para o estudante.

Dos outros 17 programas de disciplina que apresentaram mapas mentais na primeira versão, construídos a partir das orientações sobre a importância da inter-relação dos conceitos-chave, seguem três exemplos (Figuras 1 a 3). 
Figura 1 - Mapa conceitual de Eletricidade Aplicada.

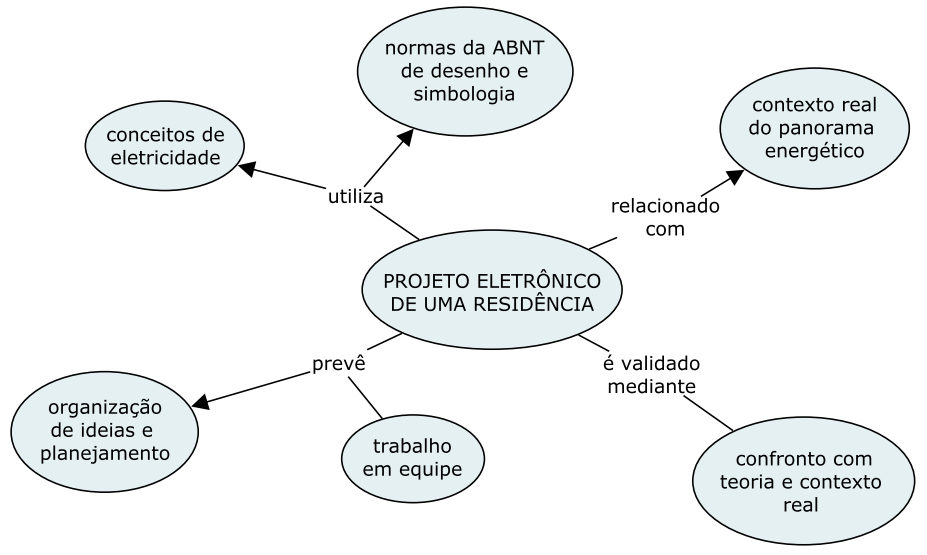

Fonte: Lília Siqueira.

Figura 2 - Mapa mental de Topografia Avançada Aplicada à Arquitetura e Design.

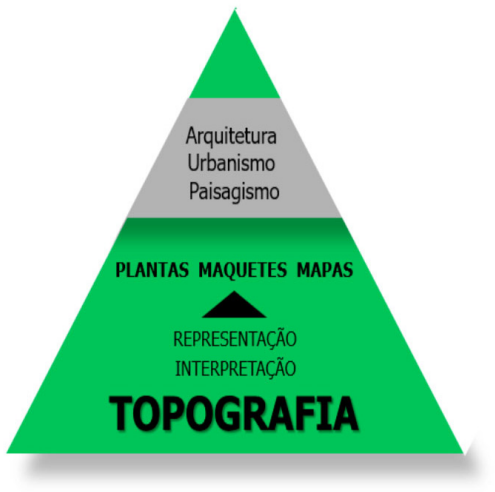

Fonte: Lúcia Maziero 
Figura 3 - Mapa mental de Química Geral.

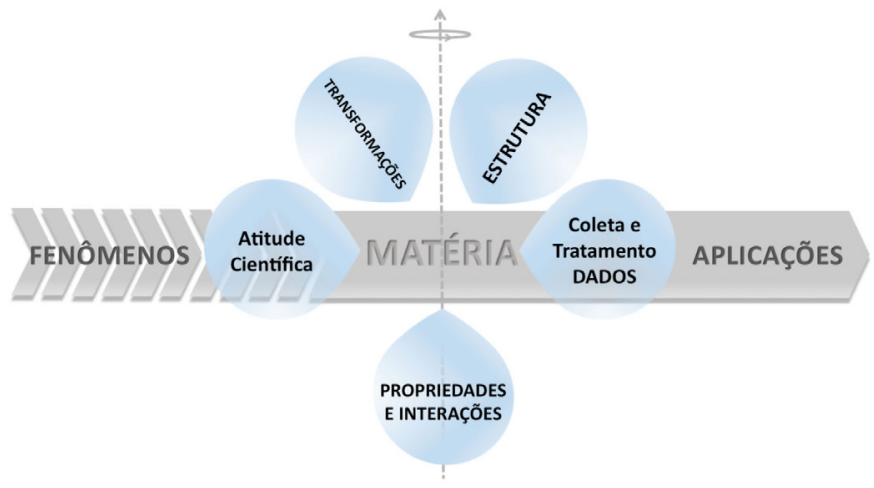

Fonte: Maria Alice Witt.

Outra categoria selecionada nos programas de disciplina referia-se aos resultados de aprendizagem, que expressam as principais aprendizagens esperadas na disciplina, devendo estar coerentes com a ementa e os mapas mentais. Precisam ser claros e concisos, mensuráveis e observáveis, além de adequados ao papel da disciplina no curso. Ainda, contribuem para que o docente reflita sobre a importância de cada tema de estudo na disciplina e escolha a estratégia de ensino e aprendizagem mais adequada.

Sobre a quantidade de resultados de aprendizagem, pode-se afirmar que, de modo geral, as disciplinas apresentaram adequação, conforme a Tabela 1.

Tabela 1-Total de resultados de aprendizagem do Plano de Ensino das disciplinas.

\begin{tabular}{c|c}
\hline Total de disciplinas & Total de resultados de aprendizagem \\
\hline 8 & 4 \\
6 & 3 \\
2 & 5 \\
1 & 6 \\
1 & 7 \\
1 & 8 \\
\hline
\end{tabular}

Fonte: As autoras (2017). 
Pode-se deduzir que um maior número de resultados de aprendizagem certamente despende mais tempo das aulas; portanto, a disciplina que elencou oito resultados, mesmo possuindo 40 horas, pode estar focada em práticas integradoras de dois ou mais resultados. Já as disciplinas com seis e sete resultados de aprendizagem possuem cada uma 80 horas.

Sobre a qualidade e a sequência lógica dos resultados de aprendizagem propostos, todos apresentaram boa sequência e estavam articulados com as palavras-chave constantes nos mapas mentais; também estavam coerentes com a ementa das disciplinas, indicando que a estrutura do Plano de Ensino contribuiu para essa adequação.

Há indicação de resultados de aprendizagem associando processos cognitivos a dimensões declarativas de conhecimento, requerendo como qualificador a perspectiva interdisciplinar. Por exemplo: "Identificar elementos estruturantes do direito societário nas diversas formas de organizações societárias, numa visão interdisciplinar" (Direito Societário). Outros relacionaram processos cognitivos a dimensões estratégicas ou condicionais de conhecimento, demandando como qualificador a perspectiva sistêmica: "Elaborar a peça processual adequada à solução do problema criminal, pautando-se em uma análise sistêmica do problema" (Estágio Supervisionado de Prática Jurídica Criminal I). Ainda, alguns resultados de aprendizagem associaram processos cognitivos a dimensões procedimentais do conhecimento, exigindo como qualificador o saber ser:

Propor ações de intervenção socioeducativa, estrategicamente elaboradas, por meio de legislações específicas e do estudo crítico da realidade socioambiental brasileira, tendo em vista a emancipação humana e a dignidade da pessoa na contemporaneidade (Educação em Direitos Humanos e Meio Ambiente).

Tomar decisões em situações de conflito moral com base em princípios éticos e da tradição filosófica (Ética).

Demonstrar apreço, compromisso e cooperação com a realização das atividades (Teoria do Conhecimento). 
Também cabe mencionar os resultados de aprendizagem da disciplina Anatomia, que demonstram a preocupação docente com a integração de conteúdos, relacionando as partes ao todo: "Identificar as partes de um corpo correlacionando o aspecto funcional com o estrutural". "Recompor o organismo, entendendo o todo a partir das partes estudadas" (Anatomia).

Outra categoria selecionada nos planejamentos de disciplina foi a metodologia. Nesta pesquisa, conforme exposto, o objetivo principal dos participantes do Projeto Finep é promover a inovação metodológica de sua prática pedagógica; portanto, esta categoria do Plano de Ensino tem relevância sobre as demais, visto permitir a promoção do trabalho cooperativo. A Tabela 2 fornece uma síntese das metodologias de aprendizagem ativa propostas no Plano de Ensino das disciplinas.

Tabela 2 - Metodologias de aprendizagem ativa no Plano de Ensino das disciplinas.

\begin{tabular}{lc}
\multicolumn{1}{c}{ Metodologia de aprendizagem ativa } & Total de planos de ensino \\
\hline Aprendizagem por pares & 14 \\
Aprendizagem baseada em times (TBL) & 3 \\
Estudo de caso & 6 \\
Aprendizagem baseada em problemas (PBL) & 9 \\
Sala de aula invertida & 9 \\
Método 300 & 1 \\
Aprendizagem baseada em projetos (PjBL) & 4 \\
Debates regulados & 1 \\
Rotação & 1 \\
Ensino sob medida & 3 \\
Aprendizagem híbrida & 1 \\
Trabalho em equipe & 2 \\
Gamificação & 1 \\
\hline
\end{tabular}

Fonte: As autoras (2017).

Fica evidente que houve uso expressivo de três metodologias: aprendizagem por pares, segundo o método proposto por Mazur (2015), PBL e sala de aula invertida. Das 13 metodologias mencionadas na Tabela 2 , seis promovem trabalho cooperativo, explicitamente, tendo sido citadas 
ao todo 24 vezes nos programas de disciplina. Por outro lado, também cabe destacar que, em oito programas, foram mencionadas aulas expositivas dialogadas. Embora essas aulas sejam consideradas pertencentes a metodologias tradicionais de ensino, estavam presentes em aproximadamente $50 \%$ dos programas de disciplina participantes do projeto de inovação pedagógica. Durante os encontros de formação continuada, os docentes justificaram o uso dessa metodologia como necessário para compor alguns momentos da aula, entre uma metodologia de aprendizagem ativa e outra, para introduzir um conteúdo desconhecido, sistematizar algum conhecimento ou fazer uma reflexão sobre alguma aprendizagem. Consideravam não haver uma regra para o uso das aulas expositivas dialogadas, pois depende da disciplina, do conteúdo e da condição dos estudantes. No entanto, todos concordaram ser preciso planejar seu uso de forma criteriosa e pontual, em determinados momentos da aula, mas sem monopolizá-la.

Finalmente, sobre a categoria "avaliação", na primeira entrega dos programas de disciplina, dois deles se destacaram pela variedade de formas, propondo atividades individuais e em grupo de modo equilibrado e indicando feedback contínuo e avaliação por pares. Outros oito programas mencionaram atividades avaliativas individuais e em grupo; seis programas citaram apenas avaliações individuais e somativas; e dois programas não mencionaram as formas de avaliação, somente o conteúdo a ser avaliado. Após as orientações e o feedback ao longo das oficinas, todos reformularam e acrescentaram alguma proposta de avaliação formativa. Isso representa não só a oportunidade de potencializar as condições de desenvolvimento dos educandos, mas também o aprimoramento do trabalho pedagógico.

\section{Discussão sobre os elementos/construtos interdisciplinares}

São evidentes os avanços de postura interdisciplinar do professor no modelo de programa de disciplina proposto, requerendo: integração entre os temas de estudo na elaboração da ementa; explicitação 
da relação de anterioridade e posterioridade das disciplinas do curso; inter-relação de conceitos-chave da disciplina, por meio de mapa mental; e inter-relação de elementos processuais do programa de disciplina, como os resultados de aprendizagem alinhados com a ementa, o mapa mental, as metodologias de aprendizagem ativa e as formas de avaliação. Essa visão integradora do planejamento prepara o docente para uma abordagem interdisciplinar e representa um exercício relevante de compreensão da unicidade e complexidade do fato educativo.

Embora tal exercício ainda não se efetive como prática interdisciplinar, no sentido exato do termo, no qual se identifica a proposta de trabalho integrado entre duas ou mais disciplinas, tem-se aqui uma proposta alternativa e eficaz de planejamento que integra os componentes do trabalho docente no interior da própria disciplina. Pode-se inferir que professores envolvidos com esse trabalho inicial do construto interdisciplinar terão suas práticas em sala de aula modificadas, indo além das metodologias do ensino tradicional.

Obviamente, alguns resultados desta análise documental expressam a dificuldade docente de situar a disciplina ministrada no curso. Isso remete à necessidade de superar o desconhecimento dos temas de estudo tratados nas diversas disciplinas de um curso, o que se configura requisito essencial para a prática interdisciplinar, pois a falta de informação impossibilita os professores de apontar possíveis contribuições das diferentes disciplinas que compõem o quadro e estabelecer parcerias de trabalho. Esse aspecto parece indicar outra necessidade maior: a integração entre o macroplanejamento de um curso (organização curricular) e o microplanejamento (cada programa de disciplina). Entretanto, numa formação continuada como esta, há a possibilidade de superar esse desafio.

Outro aspecto que merece destaque é o uso de metodologias ativas para o desenvolvimento de resultados de aprendizagem, pois estão sustentadas na valorização do agir de quem aprende, como elemento central para a compreensão de algo. Isso significa que a aprendizagem resulta da interação entre as estruturas de pensamento e aquilo que necessita ser compreendido, que é não só o conhecimento (objeto), mas também o 
outro (objeto social). $\mathrm{O}$ ato de aprender, portanto, requer um processo reconstrutivo que permita diferentes tipos de relação entre fatos e objetos, desencadeando ressignificações/reconstruções e contribuindo para sua utilização em distintas situações.

Nesse sentido, tanto as metodologias de aprendizagem ativa quanto os resultados de aprendizagem compõem elementos centrais para o construto da interdisciplinaridade, visto que a escolha dessas metodologias depende dos resultados de aprendizagem esperados; estes, por sua vez, dão sentido, intenção a essas escolhas. Nesta análise documental, fica mais explícita a perspectiva interdisciplinar docente por meio dos resultados de aprendizagem pretendidos pelos professores, conforme é possível perceber nos exemplos selecionados dos programas de disciplina. Entretanto, aplicando os conceitos de interdisciplinaridade de Lenoir e Hasni (2004) - Quadro 1 - a maioria dos resultados de aprendizagem apresenta aspectos interdisciplinares orientados para a lógica procedimental, na busca da funcionalidade social (profissionalizante), originária da cultura científica norte-americana. Em três programas de disciplina, aparecem resultados de aprendizagem voltados para a lógica subjetiva, dirigida para as dimensões humanas e afetivas, à procura do próprio ser, e originária da cultura científica emergente brasileira. Isso se explica pela própria natureza interdisciplinar dessas disciplinas, referentes à ética, à epistemologia, ao cuidado e à educação ambiental e em direitos humanos.

Outro aspecto relevante desse processo é a promoção do trabalho cooperativo oportunizado pelas metodologias de aprendizagem ativa. No trabalho em equipe, o estudante aprende a observar e escutar, a relacionar as opiniões alheias, a argumentar e contra-argumentar de forma adequada para a área do conhecimento, aceitando pensamentos e ideologias distintos dos dele. Neste estudo, identificou-se o uso de metodologias de aprendizagem ativa que favorecem o trabalho cooperativo, o que pode significar abertura para a construção de novas relações sociais entre os estudantes, possibilitando atitudes de resgate da cooperação e da solidariedade, em contraposição aos valores do individualismo e da competição, típicos da forma de ser e viver na sociedade atual. 
Este estudo apresenta, nos programas de disciplina produzidos pelos professores participantes das oficinas, uma representação genuína do complexo processo inicial de formação continuada voltada para uma prática pedagógica inovadora de uso de metodologias de aprendizagem ativa. Ao mesmo tempo, coloca-se em evidência a possibilidade de desenvolver o construto da interdisciplinaridade, por meio da visão integradora do planejamento, um passo essencial para a compreensão da complexidade do fato educativo. Nesse sentido, a postura interdisciplinar é proporcionada pela produção dos programas de disciplina, que reúne um grupo multidisciplinar de docentes em oficinas de formação continuada, favorecendo o diálogo e o natural movimento de aproximação dos planejamentos, numa perspectiva educacional de busca de inovação. Dessa forma, o próprio trabalho cooperativo entre os professores desafia-os a negociar experiências e expectativas, tendo flexibilidade para mudar temas e enfoques.

\section{Considerações finais}

A desejada e defendida interdisciplinaridade, foco deste estudo e almejada como procedimento na prática pedagógica dos professores universitários, de acordo com Nicolescu (1999, p. 45-46, grifo nosso), já precisaria dar lugar à transdisciplinaridade, que, conforme o prefixo "trans", "diz respeito àquilo que está ao mesmo tempo entre as disciplinas, através das diferentes disciplinas e além de qualquer disciplina". Seu objetivo é a compreensão do mundo presente, para o qual um dos imperativos é a religação e unidade do conhecimento. O caminho é longo, mas é possível de ser trilhado, sendo necessidade urgente, num primeiro momento, alcançar a interdisciplinaridade e, com seu avanço, a transdisciplinaridade.

Um processo educativo que atenda ao paradigma da complexidade precisa desenvolver processos metodológicos, nos quais, segundo Freire (1992), o estudante seja percebido como um sujeito construtor de sua própria história, consciente de si mesmo, capaz de se perceber e de se 
compreender como cidadão na sociedade, o que requer inserir nos programas de disciplina a interdisciplinaridade de lógica subjetiva, a qual busca a dimensão humana e afetiva e valoriza como ele pensa, sente, reage, vive e convive.

\section{Agradecimentos}

À Finep - Inovação e Pesquisa, que possibilitou esta pesquisa, bem como as iniciativas em inovação na graduação. À Profa. Patrícia Lupion Torres, pelas contribuições relevantes feitas tanto na disciplina Seminário de Aprofundamento: Teoria e Prática Pedagógica na Formação de Professores quanto na revisão deste artigo científico.

\section{Referências}

ADORNO, T. W. Notas marginais sobre teoria e práxis. In: ADORNO, T. W. Palavras e sinais: modelos críticos. Petrópolis: Vozes, 1995.

BEHRENS, M. A. Contributos de Edgar Morin e Paulo Freire no paradigma da complexidade. In: BEHRENS, M. A.; ENS, R. T. (Org.). Complexidade e transdisciplinaridade: novas perspectivas teóricas e práticas para a formação de professores. Curitiba: Appris, 2015.

CARVALHO, I. C. M. Educação ambiental: a formação do sujeito ecológico. 4. ed. São Paulo: Cortez, 2004.

CONTRERAS, J. Autonomia de professores. São Paulo: Cortez, 2002.

COORDENAÇÃO DE APERFEIÇOAMENTO DE PESSOAL DE NÍVEL SUPERIOR (CAPES). Diretoria de Avaliação. Documento de área. 2013. Disponível em: <http://capes.gov.br/images/stories/download/avaliacaotrienal/Docs_de_area/ Interdisciplinar_doc_area_e_comiss\%C3\%A3o_block.pdf >. Acesso em: 2 maio 2017. 
CRESWELL, J. W. Projeto de pesquisa: métodos qualitativo, quantitativo e misto. 2. ed. Porto Alegre: Artmed, 2007.

DELUIZ, N. A globalização econômica e os desafios à formação profissional. Boletim técnico do SENAC, v. 22, n. 2, 1996. Disponível em: 〈http://www.cefetsp.br〉. Acesso em: 17 abr. 2017.

FAZENDA, I. C. Integração e interdisciplinaridade no ensino brasileiro: efetividade ou ideologia. São Paulo: Loyola, 1979.

FERRAZ, A. P. C. M.; BELHOT, R. V. Taxonomia de Bloom: revisão teórica e apresentação das adequações do instrumento para definição de objetivos instrucionais. Gestão \& Produção, São Carlos, v. 17, n. 2, p. 421-431, 2010. Disponível em: <http:// www.scielo.br/pdf/gp/v17n2/a15v17n2>. Acesso em: 10 maio 2017.

FREIRE, P. Pedagogia da esperança: um reencontro com a pedagogia do oprimido. Rio de Janeiro: Paz e Terra, 1992.

LEIS, H. R. Sobre o conceito de interdisciplinaridade. Cadernos de Pesquisa Interdisciplinar em Ciências Humanas, Florianópolis, v. 6, n. 73, p. 1-23, ago. 2005. Disponível em: <https://periodicos.ufsc.br/index.php/cadernosdepesquisa/article/ view/2176/4455>. Acesso em: 1 maio 2017.

LENOIR, Y.; HASNI, A. La interdisciplinaridad: por um matrimonio abierto de la razón, de la mano y del corazon. OEI - Revista Iberoamericana de Educación, n. 35, maio/ago. 2004. Disponível em: 〈http://www.rieoei.org/rie35a09.htm>. Acesso em: 1 maio 2017.

MARCELO GARCÍA, C. Formação de professores: para uma mudança educativa. Porto: Porto, 1999.

MAZUR, E. Peer instruction: a revolução da aprendizagem ativa. Porto Alegre: Penso, 2015.

MORIN, E. Os sete saberes necessários à educação do futuro. São Paulo: Cortez, 2000.

NICOLESCU, B. O manifesto da transdisciplinaridade. São Paulo: Trom, 1999. 
OLIVEIRA, V. F. Professor universitário: saberes e demandas profissionais. In: MOROSINI, M. C. (Org.). Enciclopédia de pedagogia universitária. Porto Alegre: FAPERGS/RIES, 2003.

PIMENTA, S. G.; ANASTASIOU, L. G. C. Docência no ensino superior. São Paulo: Cortez, 2002.

SANTOS, E. H. A interdisciplinaridade como eixo articulador do ensino médio e do ensino técnico de nível médio integrados. In: Ministério da Educação/Secretaria de Educação Básica. Ensino médio integrado à educação profissional: integrar para quê? Brasília: MEC/SEB, 2006. p. 139-153.

SANTOS, E.; SILVA, M. A pedagogia da transmissão e a sala de aula interativa. In: TORRES, P. L. (Org.). Complexidade: redes e conexões na produção do conhecimento. Curitiba: SENAR-PR, 2014.

SERRA, C. H. A.; BECKER, J. Globalização: influência e desafios enfrentados na mudança do paradigma da formação profissional. In: SIMPÓSIO DE EXCELÊNCIA EM GESTÃO E TECNOLOGIA, 8., 2011, Rio de Janeiro. Anais... [S.l.: s.n.], 2011. Disponível em: <http://chpenhaprojetoseducacionais.blogspot.com.br/2011/04/ viii-simposio-de-excelencia-em-gestao-e.html $>$. Acesso em: 16 abr. 2017.

TARDIF, M. Saberes docentes \& formação profissional. Petrópolis: Vozes, 2002.

TORRES, P. L.; BEHRENS, M. A. Complexidade, transdisciplinaridade e produção de conhecimento. In: TORRES, P. L. (Org.). Complexidade: redes e conexões na produção do conhecimento. Curitiba: SENAR-PR, 2014.

ZABALA, A. A prática educativa. Porto Alegre: Artmed, 1998.

Recebido: 09/04/2017

Received: 04/09/2017

Aprovado: 01/06/2017

Approved: 06/01/2017 